\title{
A FUNÇÃO SIMBÓLICA DA PENA NO BRASIL BREVE CRÍTICA À FUNÇÃO DE PREVENÇÃO GERAL POSITIVA DA PENA CRIMINAL EM JAKOBS
}

\section{Maurício Stegemann Dieter}

Acadêmico do quinto ano de Direito da Universidade Federal do Paraná.

Bolsista do Programa PET Direito.

e-mail: mauriciodieter@yahoo.com.br

RESUMO: O sistema de política penal no Brasil gravita ao redor da idéia nuclear de pena, explicada usualmente como resposta oficial à violação de um bem jurídico. Dado seu caráter instrumental, o discurso oficial historicamente atribui à pena criminal, funções que são incompatíveis com a realidade de sua aplicação; pode-se afirmar, inclusive, que as funções atribuídas à pena no Brasil (e entre elas, especialmente a função de prevenção especial) caracterizaram-se sempre como retórica. De fato, não é interessante para o discurso do poder anunciar as funções reais cumpridas pela pena, pois é insustentável um sistema de política criminal que assume a pena como instrumento de manutenção da estrutura de classes, como evidenciou a Criminologia Radical. A inexistência ou incapacidade absoluta das instituições responsáveis pelo cumprimento da pena evidencia uma crise de legitimação da pena tradicionalmente fundada na retribuição e prevenção, conceitos construídos a partir da ideologia oficial e determinados pelo centro do poder econômico. Assim, as funções formais da pena estão em contínua redefinição, oscilando a fundamentação da pena nos limites entre a retribuição total e a prevenção absoluta, perpetuando as relações de poder definidas pela distribuição desigual dos modos de produção. Na busca de novas formas de legitimação para a manutenção da ordem estabelecida surge na doutrina alemã o resgate da função de prevenção geral positiva, fundada na necessidade de manutenção de expectativas comportamentais normativas. Revela-se oportuna a crítica teórica a esta proposta, bem como a indicação de seus efeitos, os quais são manifestamente contrários à concepção de Direito Penal mínimo.

PALAVRAS-ChAVE: Direito Penal do Inimigo. Criminologia Radical. Pena. Retribuição. Prevenção geral. Função simbólica. 


\title{
1. INTRODUÇÃO
}

\section{Todo o sistema de política penal ${ }^{1}$ no Brasil gravita ao redor idéia nuclear de} pena, explicada usualmente como resposta oficial à violação de um bem jurídico ${ }^{2}$ protegido pelo Direito Penal ${ }^{3}$. Consoante essa característica, a pena constitui-se em principal (se não única) resposta do programa de política penal do Estado para o crime e criminalidade 4 .

Deste modo, dado seu caráter instrumental, o discurso ${ }^{5}$ oficial historicamente atribui à pena criminal funções que são incompatíveis com a realidade de sua aplicação; pode-se afirmar, inclusive, que as funções atribuídas à pena no Brasil (e por todas, especialmente a função de prevenção especial) caracterizaram-se

\begin{abstract}
${ }^{1}$ Não é sem propósito que o termo "política penal" é utilizado aqui como sinônimo de "política criminal". Para resolver a confusão conceitual entre "política criminal" e "política penal", é necessária a lição de Juarez Cirino dos Santos: "No Brasil e, de modo geral, nos países periféricos, a política criminal do Estado exclui políticas públicas de emprego, salário, escolarização, moradia, saúde e outras medidas complementares, como programas oficiais capazes de alterar ou reduzir as condições sociais adversas da população marginalizada do mercado de trabalho e dos direitos de cidadania, definíveis como determinações estruturais do crime e da criminalidade; por isso, o que deveria ser a política criminal do Estado existe, de fato, como simples política penal instituída pelo Código Penal e leis complementares - em última instância, a formulação legal do programa oficial de controle social do crime e da criminalidade: a definição de crimes, a aplicação de penas e a execução penal, como níveis sucessivos da política penal do Estado, representam a única resposta oficial para a questão criminal”. SANTOS, Juarez Cirino dos. Teoria de Pena: fundamentos políticos e aplicação judicial; p. 1.
\end{abstract}

${ }^{2}$ A definição de bem jurídico é uma opção ideológica. Decidir o que merece tutela penal significa atribuir a certas condutas o caráter criminal, o que autoriza uma ação coercitiva do Estado. Expõe GARCíA: "(...) não se pode recorrer ao direito penal, enquanto instrumento de controle social, senão para a necessária proteção dos interesses humanos mais elementares, sempre e quando não se possa dispor de outros instrumentos mais inofensivos para lograr essa proteção". GARCíA, Olga Lucia Gaitán. Direito penal contemporâneo: da tutela pena a uma lesão à proteção de riscos; p. 42.

${ }^{3}$ Segundo Gilberto Ferreira, "a pena é a conseqüência jurídica - o mal que se impõe -, que implica a diminuição de bens jurídicos, ao autor imputável de fatos descritos na lei como crimes".FERREIRA, Gilberto. A Aplicação da Pena; p. 4 e 5. O autor ainda lista na página anterior uma série de definições sobre o caráter da pena. Parece-me importante salientar que ele acertadamente escapa do erro conceitual ao qual se renderam a maioria dos autores, pois não confunde o conceito de pena com suas funções. Neste sentido comparar com JESUS, Damásio E. de. Direito Penal. 8ª ed. São Paulo: Saraiva, 1983. p. 475

4 "A história das transformações do sistema penal, na perspectiva da relação entre base econômica e mecanismos superestruturais de controle, de Rusche a Kirchheimer, representa um avanço real da teoria criminológica radical: são as relações do mercado de trabalho, no período capitalista, que explicam a generalização da prisão como método de controle e disciplina das relações de produção (fábrica) e de distribuição (mercado), com o objetivo de formar um novo tipo humano: a força de trabalho necessária e adequada ao aparelho produtivo". SANTOS, Juarez Cirino dos. A Criminologia Radical; p. 43.

5 Emprega-se o vocábulo "discurso" no sentido atribuído por Chaïm Perelman e Lucie Olbrechts-Tyteca no livro Tratado da Argumentação. Explicitando ainda mais a compreensão proposta, discurso aqui se refere às manifestações que legitimam as ações repressivas do Estado contra o cidadão submetido. A partir de um local simbólico, o Estado estabelece sua argumentação tendo por auditório universal (o qual pretende convencer) o senso comum e auditório particular (o qual pretende persuadir) a classe dominante. Evidente, portanto, que raramente as razões (ou convicções) serão semelhantes às racionalizações (ou justificações) do discurso. Desta forma, a melhor definição de "discurso do poder" está relacionada com as características típicas da propaganda: o discurso do poder na modernidade estaria caracterizado como propaganda, pois não é porta-voz dos consensos, atuando no convencimento e normalização até alcançar o custo de legitimação suficiente para determinada ação política. Para o estudo desta importante área da lógica, e para compreensão das formas pelas quais autoriza-se a aplicação simbólica da pena, imprescindível a leitura da obra mencionada. 
sempre como retórica ${ }^{6}$, pois nunca constituíram um projeto real na política penitenciária implementada pelo Estado. Evidente, consoante esta lógica, que não interessa ao discurso do poder anunciar as funções reais cumpridas pela pena, pois insustentável um sistema de política criminal que a assume como instrumento de manutenção da estrutura de classes, como evidenciou a Criminologia Radical ${ }^{7}$.

A inexistência ${ }^{8}$ ou incapacidade absoluta das instituições responsáveis pelo cumprimento da pena ${ }^{9}$ evidencia uma crise de legitimação da pena tradicionalmente fundada na retribuição e prevenção ${ }^{10}$, conceitos construídos a partir da ideologia oficial e determinados pelo centro do poder econômico.

Neste sentido, as funções formais da pena estão em contínua redefinição, oscilando sua legitimação da pena nos limites definidos entre a retribuição e a prevenção, de modo a perpetuar as relações de poder definidas pela distribuição desigual dos modos de produção. Verificada a clivagem abissal entre as funções declaradas e a realidade de sua execução, o Direito Penal busca novas formas de legitimação desta idéia fundamental para a manutenção da ordem estabelecida.

$\mathrm{Na}$ atual busca de novos recursos argumentativos que autorizem a pena, surge na doutrina alemã, embasada em uma nova construção sociológica, o resgate da função de prevenção geral positiva, fundada na necessidade de manutenção de expectativas comportamentais normativas ${ }^{11}$. Revela-se oportuna a crítica teórica a esta proposta, bem como a indicação de seus efeitos, os quais são manifestamente

6 "Os problemas do sistema penal são sempre conjunturais, e o melhor exemplo é a penitenciária. A despeito de todos os relatórios (...) apontarem para a irremediável deterioração do emprisionamento sobre sua clientela, de que as taxas de reincidência penitenciária são o menos expressivo sinal, a boa penitenciária nos aguarda, num futuro eternamente adiado". BATISTA, Nilo. Mídia e sistema penal no capitalismo tardio; p. 274.

7 SANTOS, Juarez Cirino dos. A Criminologia Radical.

${ }^{8}$ Como é exemplo a Casa do Albergado na imensa maioria dos municípios.

${ }^{9}$ Como uma rápida visita ao Centro de Triagem de Piraquara pode evidenciar.

${ }^{10}$ Modelo adotado no Brasil, nos termos do artigo 59 do Código Penal Brasileiro.

11 Hipótese que não possui elementos inéditos, como demonstra CIRINO DOS SANTOS: “(...) HEGEL (1770 - 1831) define crime como negação do direito e pena como negação da negação e, portanto, como reafirmação do direito - uma antecipação de dois séculos da prevenção geral positiva de JAKOBS, da pena como afirmação da validade da norma (...)". SANTOS, Juarez Cirino dos. A Teoria da Pena; p.5. 
contrários à concepção de Direito Penal mínimo, único compatível com um Estado Democrático de Direito ${ }^{12}$.

\section{AS FUNÇÕES ATRIBUÍDAS À PENA NO DISCURSO OFICIAL}

O Direito Penal é o instrumento mais agudo de intervenção do comportamento coletivo, devendo ser sempre encarado com último recurso para o controle social consoante o "princípio da intervenção mínima, que decorre do caráter subsidiário do direito penal. Só deve o Estado intervir com a sanção jurídico-penal quando não existam outros remédios jurídicos, ou seja, quando não bastarem as sanções jurídicas do direito privado. A pena é a ultima ratio do sistema"13: somente quando esgotadas todas as possibilidades de sanção alternativa, deve ele apresentar-se como meio para solucionar os conflitos $^{14}$.

A proteção dos valores fundamentais da vida social, encarados como "bens jurídicos" caracterizaria, segundo o discurso dominante, a função maior do Direito Penal, e como tratamos aqui de elementos essenciais, é óbvio que "apenas os bens jurídicos vitais ao desenvolvimento equilibrado da vida comunitária devem merecer a especial tutela do Direito Penal"15; somente assim garantir-se-ão a segurança e a estabilidade do juízo ético-penal, reagindo contra a violação dos bens jurídicos de acordo com os princípios que o norteiam, reafirmando a confiança coletiva nas instituições.

A discussão em torno das funções do Direito Penal está intrinsecamente conectado ao programa de política criminal oficial instituído pela dogmática penal. $\mathrm{A}$ partir das funções atribuídas denotam-se as funções declaradas da pena, como resposta oficial do sistema de justiça criminal (polícia, judiciário e instituições prisionais) para o fato punível.

12 Especialmente porque é na limitação imposta ao poder de punir que encontramos os contornos da democracia: "O direito penal é de fato o terreno sob o qual, da maneira mais emblemática, se manifestam os limites da democracia política, entendida como o poder ou vontade do povo e, portanto, da maioria".FERRAJOLI, Luigi. A pena em uma sociedade democrática; p. 31.

${ }^{13}$ FRAGOSO, Heleno Cláudio. Lições de Direito Penal; p. 290

14 A função "ético-social" e "preventiva" de WELZEL, assume assim outros contornos que não respondem às exigências imediatistas e vingativas da massa.

${ }^{15}$ MONTEIRO DE BARROS, Flávio Augusto. Direito Penal; p.3. 
De acordo com a opinião majoritária nesta seara, o Direito Penal cumpriria duas funções essenciais: ético-social e preventiva.

A função ético-social é feita através da proteção dos valores fundamentais da vida social, os quais merecem esta proteção legal exatamente em razão de sua significação social. Assim, ao punir condutas humanas, o Direito Penal estabelece quais são as condutas apropriadas para uma coletividade ${ }^{16}$, reafirmando seus os princípios éticos sociais ${ }^{17}$. Como conseqüência da função ético-social do direito penal, atribui-se à pena criminal a função de retribuição, definida como mal proporcional do crime, inspirada na tradição da moral cristã e filosofia idealista, e quantificada de acordo com a culpabilidade ${ }^{18}$.

A crítica em relação ao discurso retributivo nega-lhe o caráter democrático e científico:

"Não é democrático porque no Estado Democrático de Direito o poder é exercido em nome do povo - e não em nome de Deus - e, além disso, o Direito Penal não tem por objetivo realizar vinganças, mas proteger bens jurídicos. Por outro lado, não é científico porque a retribuição do crime pressupõe um dado indemonstrável: a liberdade de vontade do ser humano $(\ldots)^{, 19}$

Ainda segundo este discurso doutrinário dominante, além da função éticosocial, caberia ao Direito Penal (e conseqüentemente à pena como elemento central) uma função preventiva, em duas variantes, das quais decorrem ainda, duas funções específicas: a prevenção geral em sua forma positiva cumpriria o papel de normalizar as relações sociais, garantindo a ordem através da estabilização das expectativas da sociedade, e em sua forma negativa, por meio do poder intimidante que caracteriza o Direito Penal, funcionaria como inibidora de futuras ações criminosas pela certeza da punição; já a prevenção especial dá-se negativamente através da "neutralização" do sujeito criminoso (ou criminalizado), do coletivo social

${ }^{16}$ A hipocrisia deste pensamento salta aos ohos: nunca o Código Penal vai refletir "princípios éticosociais" outros que os da classe dominante, exceto em uma democracia materialmente manifesta, como já propôs a Criminologia Crítica. Assim BARATTA, Alessandro. Criminologia crítica e crítica do direito penal.

${ }^{17} \mathrm{O}$ que necessariamente aproxima sua função da prevenção geral positiva atribuída à pena.

18 SANTOS, Juarez Cirino dos. Teoria da Pena; p.3-5.

${ }^{19}$ SANTOS, Juarez Cirino dos. Teoria da Pena; p. 5 e 6. 
pelo isolamento ${ }^{20}$, e positivamente por meio da reeducação ${ }^{21}$ do detento na execução da pena ${ }^{22}$.

A crítica à prevenção geral positiva constitui tópico próprio no presente trabalho e será analisada adiante. Já em relação a prevenção geral negativa, a crítica demonstra que ela é ineficaz em seu efeito intimidante, como evidencia qualquer análise histórica: some-se a isso a falta de um critério limitador para a ação de intimidação e a violação à dignidade da pessoa humana inerente a esta estratégia de controle social ${ }^{23}$.

A prevenção especial também está sujeita a críticas teóricas: em sua forma negativa, porque baseada em premissa inconstitucional e impossível de aplicação ampla, e em sua vertente positiva porque os programas de ressocialização no Brasil sequer podem ser considerados fracassados, vez que nunca foram realmente propostos no programa de política criminal.

Conforme a opção do legislador brasileiro, adota-se a teoria unificada da pena, atribuindo-Ihe ambas prerrogativas, o que se evidencia no artigo 59 do Código Penal Brasileiro, o qual estabelece que a pena deve ser suficiente para a retribuição e prevenção do crime ${ }^{24}$.

Conclui-se portanto que, longe de preocupar-se com os efeitos reais da pena, o ordenamento nacional faz a opção voluntária de anunciar as funções aptas a manutenção do discurso reprodutor da ordem vigente.

20 "A prevenção especial negativa de neutralização do criminoso, baseada na premissa de que a privação de liberdade do condenado produz segurança social, parece óbvia: a chamada incapacitação seletiva de indivíduos considerados perigosos constitui efeito evidente da execução da pena, porque impede a prática de crimes fora dos limites da prisão - e, assim, a neutralização do condenado seria uma das funções manifestas ou declaradas cumpridas pela pena criminal". SANTOS, Juarez Cirino dos. Teoria da Pena: fundamentos políticos e aplicação judicial. Curitiba: ICPC/Lumen Júris, 2005. p. 7 e 8.

${ }^{21}$ A prevenção especial positiva é a principal função atribuída à pena no discurso oficial atual, e está formalmente prevista no artigo $1^{\circ}$ da Lei de Execuções Penais: Art. $1^{\circ}$ A execução penal tem por objetivo efetivar as disposições de sentença ou decisão criminal e proporcionar condições para a harmônica integração social do condenado e do internado.

22 “(...) a prevenção especial positiva de correção (ou de ressocialização, ou de reeducação etc.) do criminoso, realizada pelo trabalho de psicólogos, assistentes sociais e outros funcionários da ortopedia moral do estabelecimento penitenciário, durante a execução da pena - segundo outra fórmula antiga: punitur, ne peccetur'. SANTOS, Juarez Cirino dos. Op. Cit. p. 7.

23 "Essa crítica relativizou a teoria e colocou em discussão outra de maior entidade, de acordo com a qual a prevenção intimidatória lesiona a dignidade do homem enquanto utiliza a pessoa, como meio para a intimidação de outra e. ademais, não é crível em seus efeitos reais, posto que parte de suposições tão difíceis de satisfazer como o conhecimento por parte de todos os cidadãos, das sanções penais e das condenações, e da motivaçõa dos cidadão honrados pela cominação e execução penal”. GARCIA, Olga Lucía Gaitán. Op. Cit. p. 43. 


\section{AS VERDADEIRAS FUNÇÕES DA PENA: UMA REFLEXÃO A PARTIR DA CRIMINOLOGIA RADICAL}

Evidenciadas as funções declaradas da pena pelo discurso oficial, bem como seu completo fracasso, torna-se necessário refletir sobre as funções ocultas da pena as quais, longe de constituírem uma teoria improvável de matizes subversíveis, explicitam-se em uma análise meramente superficial. Entretanto, ainda que evidentes, estas funções são encobertas pelo engodo das funções declaradas, cantilena hipócrita do discurso repressivo repetida pela dogmática conivente.

A Criminologia Radical rompe com a ilusão das funções declaradas da pena, evidenciando a necessária conexão entre as relações de poder determinadas pela distribuição desigual dos meios de produção, e pela sujeição mediante trabalho assalariado e a política penal do Estado. Explicita-se, pela visão marxista, uma explicação materialista para o papel desempenhado pela pena na intenção de perpetuar as relações de poder:

"O objetivo real mais geral do sistema de justiça criminal (além da parência ideológica e da consciência honesta de seus agentes) é a moralização da classe trabalhadora, através da inculcação de uma 'legalidade de base': o aprendizado das regras da propriedade, a disciplina no trabalho produtivo, a aestabilidade no emprego, na família, etc. A utilidade complementar da constituição de uma 'criminalidade de repressão' (localizada nas camadas oprimidas da sociedade e objeto de reprodução institucional) é camuflar a criminalidade dos opressores (abuso de poder político e econômico), com a tolerância das leis, a indulgência dos tribunais e a discrição da imprensa" 25

O mercado de trabalho, determinante do sistemas de punição adotado pelo Estado é determinado pela seguinte lógica: "se a força de trabalho é insuficiente para as necessidades do mercado, o sistema penal adota métodos punitivos de preservação da força de trabalho; se a força de trabalho excede as necessidades do mercado, o sistema penal adota métodos punitivos de destruição da força de trabalho"26.

${ }^{24}$ Art. 59. O juiz, atendendo à culpabilidade, aos antecedentes, à conduta social, à personalidade do agente, aos motivos, às circunstâncias e conseqüências do crime, bem como ao comportamento da vítima, estabelecerá, conforme seja necessário e suficiente para reprovação e prevenção do crime.

${ }^{25}$ SANTOS, Juarez Cirino dos. A Criminologia Radical; p. 58.

${ }^{26}$ SANTOS, Juarez Cirino dos. Teoria da Pena; p. 20. 
Estabelece-se desta forma a função da pena sob o princípio da retribuição equivalente, uma característica essencial da estrutura material das relações econômicas fundadas no capitalismo ${ }^{27}$. A contribuição do marxismo, por meio da Criminologia Radical evidencia que a pena (e em especial a pena privativa de liberdade), serve perfeitamente à manutenção da sujeição inerente a este sistema, o qual é historicamente fundado no binômio cárcere - fábrica (fábrica para aqueles que se sujeitam às condições impostas - como instrução, submissão, etc - e cárcere para os marginalizados). Desta forma, a verdadeira função resume-se a reproduzir as relações sociais de dominação de classe, o que ocorre de três modos: pela retribuição (determinada pelo tempo de contingência do indivíduo), pela prevenção especial (disciplinando o condenado na ideologia oficial) e pela prevenção geral (pela preservação da ordem social fundada na relação capital - trabalho) ${ }^{28}$.

\section{O DIREITO PENAL DO INIMIGO: JAKOBS E A FUNÇÃO DE PREVENÇÃO GERAL}

Devido à crise que atinge o argumento central de justificação da imposição de pena, o discurso da dogmática penal comprometida com as reais funções da sanção criminal apresenta, travestido de novidade, novos pressupostos para legitimar a pena no plano simbólico. Referida construção teórica tem como elemento condutor as premissas sociológicas de Luhmann, quem confere ao direito uma tarefa específica:

“(...) a função do direito reside em sua eficiência seletiva, na seleção de expectativas comportamentais que possam ser generalizadas em todas as três dimensões, e essa seleção, por seu lado, baseia-se na compatibilidade entre determinados mecanismos das generalizações temporal, social e prática (...) e podemos agora definir o direito como estrutura de um sistema social que se baseia na generalização congruente de expectativas comportamentais normativa ${ }^{29,}$.

Esta Sociologia do Direito, baseada na categoria sistema, projeta-se para o Direito Penal e caracteriza como função principal da pena a manutenção das

\footnotetext{
27 Idem. p. 21.

${ }^{28}$ Conforme SANTOS, Juarez Cirino dos. Teoria da Pena; p. 23.

29 LUHMANN, Niklas. Sociologia do Direito; p. 116
} 
expectativas comportamentais normativas, o que ocorre especialmente através da prevenção geral positiva, que se transforma em retributiva quando impulsionada pela lógica vingativa da sociedade ${ }^{30}$. Jakobs, na construção de uma teoria nova (apenas na aparência) para legitimação da pena, vale-se do sistema de expectativas criado por Luhmann. Assim, para todos os casos de violação de bens jurídicos culturalmente importantes, aos quais a mídia dedica-se com particular entusiasmo, e cuja conseqüência é a inevitável reação popular exigindo punições para o caso concreto, o magistrado convertido em responsável por reestabilizar a "pax societatis", vê-se (no mínimo) inclinado ou (no máximo) moralmente obrigado, a condenar o(s) réu(s) destes casos que mais afetam a consciência coletiva, pois em caso contrário estaria frustrando as expectativas normativas da sociedade, causando um desequilíbrio na ordem social e uma desconfiança nas instituições. A mudança é evidente: não é mais avaliado o caso concreto, apenas ponderado o perigo (em abstrato) que uma decisão possa causar nas instituições; protege-se o modelo (a ordem vigente) antes das garantias cidadãs.

A primeira crítica que cabe aqui é que não é função do Direito Penal fazer a manutenção das instituições do Estado através da manutenção de expectativas normativas, pois possui como funções próprias ${ }^{31}$ a função ético-social e a preventiva, já mencionadas.

Em segundo lugar, um Direito Penal cuja função é a manutenção das expectativas normativas leva inevitavelmente ao desrespeito do devido processo legal, pois há um pré-julgamento do réu, quem já foi condenado antes mesmo de ser julgado. Por conseguinte, a não evidente ilegalidade de alguns crimes em contraponto àqueles que integram notadamente a psique social não estabiliza, pelo contrário, desestabiliza a ordem social em uma volta ao medievo.

Finalmente, podemos concluir que, em última análise, o Direito Penal como instrumento para manutenção destas expectativas ${ }^{32}$ torna-se retributivo e injusto, situação em que os princípios perdem para o imediatismo da sanção penal.

${ }^{30}$ Assim, BRANDÃO, Cláudio. Introdução ao Direito Penal; p. 21 a 29.

31 Evidente que estas são as funções do discurso oficial fundante: as reais intenções da pena já foram explicitadas em tópico anterior. repressivo.

32 Essas expectativas nada mais são do que figuras de linguagem que migram par ao discurso 


\section{CONCLUSÃO}

Isso conduz à reflexão da motivação que impulsiona essa nova busca de legitimação da pena. Em primeiro lugar, a prevenção geral positiva aumenta o raio de ação do Direito Penal, o que aumenta o espaço para a ação arbitrária do Estado que, por falta de competência democrática e vontade política, prefere as medidas das imediativistas e visíveis das sanções penais, o que está na base dos Estados totalitários.

A pena não é solução para pacificação de conflitos sociais: o incremento da intensidade das penas e sua utilização como medida não excepcional de intervenção estatal $^{33}$, revela apenas uma sociedade incapaz de lidar com o problema da criminalidade, por ausência de políticas públicas de inclusão social, aptas a diminuir a desigualdade presente em todo o sistema social determinado pelo capitalismo.

A verdade é que, devido ao evidente fracasso das instituições estatais, e com a crescente pressão popular retributiva sobre os crimes cometidos contra a coletividade impulsionada pelo apelo da mídia, a pena criminal, devido ao seu efeito intimidante, transforma-se subitamente em único instrumento capaz de corrigir as distorções da sociedade, cuja origem provém do fracasso do sistema gestor ${ }^{34}$. A função retributiva, travestida de prevenção geral desencadeada pela população relaciona-se com a violação da ordem social, na qual o indivíduo sofre a imposição de uma pena segundo um gradiente diretamente proporcional a importância do bem jurídico lesionado, em outras palavras, um retorno a "lei do talião". Esta idéia de defesa da sociedade contra o mundo do crime é nefasta: "a idéia de defesa social (...) têm como êxito inevitável o terrorismo penal"35.

O utilitarismo da pena não encontra respaldo constitucional, pois a proteção da hipótese sobre a lesão concreta significa um adiantamento da pena, injustificado pela

33 "A sanção pena ocupa, no sistema geral de controle social, uma posição proeminente, constituindo a forma de intervenção mais aguda nos direitos dos infratores, o que se justifica pelo caráter grave do conflito penal e, por isso, ela só se impõe quando os outros mecanismos de controle social não podem resolvê-lo". GARCÍA, Olga Lucia Gaitán. Direito penal contemporâneo; p. 43.

${ }^{34}$ Uma das possibilidades que o discurso da prevenção geral autoriza, é a responsabilidade penal da pessoa jurídica, uma hipótese incompatível com o Direito Penal. Neste sentido: "o discurso da função preventiva, especialmente a preventiva geral positiva, não pode ser encarado como legitimador de novas hipóteses de criminalização; dotar a pessoa jurídica de capacidade penal significa exceder os limites da função atribuída ao Direito Penal. Neste sentido, as funções preventivas em relação às pessoas jurídicas são estabelecidas pelo direito Civil e Administrativo, não sendo necessário ou ideal aumentar o raio de ação do Direito Penal sob pena de modificar 'de baixo para cima' o programa de política criminal do Estado". DIETER, Maurício Stegemann. A Responsabilidade Penal da Pessoa Jurídica; p. 151 e 152.

${ }^{35}$ FERRAJOLI, Luigi. A pena em uma sociedade democrática; p. 31. 
impossibilidade de predizer o futuro. O resgate do (ainda possível) Direito Penal mínimo, ainda que não impeça a aplicação da pena de manter a divisão desigual do capital, é a alternativa compatível com a principiologia constitucional, como afirma Ferrajoli,

“Contra esse 'utilitarismo' dividido, o paradigma do direito penal mínimo assume como única justificação do direito penal o seu papel de lei do mais fraco em contrapartida à lei do mais forte, que vigoraria na sua ausência; portanto, não genericamente a defesa social, mas sim a defesa do mais fraco, que no momento do delito é a parte ofendida, no momento do processo é o acusado e, por fim, no momento da execução, é o réu." ${ }^{36}$

Assim, podemos concluir que devido à ineficiência do Estado em estabelecer um programa de política criminal que não se reduza à política penal, o legislador apela para a atuação do Direito Penal em ambientes e situações que não Ihe são autorizadas.

No Brasil, com todas as suas carências, dificuldades e desigualdade, a pena como símbolo do poder, tem como conseqüência apenas a manutenção das comunidades marginalizadas, identificadas como reduto que produz e reproduz a violência, exportada para a "sociedade dos homens de bem". Urge, neste sentido, não apenas denunciar as reais funções cumpridas pela pena em países de capitalismo tardio, mas procurar impedir também na retórica que as racionalizações da pena na dogmática penal ${ }^{37}$ e no programa de política penal do Brasil que as penas cumpram uma função que é incompatível com a ordem jurídica nacional, fundada na Constituição de 88. Afinal, é na limitação das penas que encontramos a reafirmação de um Estado Democrático de Direito ${ }^{38}$.

${ }^{36}$ FERRAJOLI, Luigi. A pena em uma sociedade democrática; p. 32.

${ }^{37}$ A perspectiva pessimista não é, nada obstante, conformista: "Posto que, a médio prazo, não se vê como seja possível mudar as formas atuais de controle social, é possível afirmar que a sanção penal sobreviverá com outras formas de controle social. Em conseqüência, somente é possível chegar a entender a tarefa da pena, tema central da teoria penal, se se coloca a pergunta acerca do que distingue o controle social penal das demais formas de controle social. A resposta é sua formalização, nos termos descritos no parágrafo anterior, isto é, como limite ao controle e garantia aos cidadãos". GARCíA, Olga Lucia Gaitán. Direito penal contemporâneo; p. 43.

38 “(...) a civilização de um país, advertia Montesquieu, se mede e progride com a moderação das penas. Portanto, talvez seja possível empreender hoje, com a distância de dois séculos, um novo salto de civilização: destituir a reclusão carcerária de seu papel de pena principal e paradigmática e, senão aboli-la, ao menos reduzir drasticamente sua duração e transformá-la em sanção excepcional limitada às ofensas mais graves ao direito fundamental (como à vida, à integridade pessoal e outros similares), os quais justificam, somente eles, a privação da liberdade pessoal, que é um direito fundamental constitucionalmente garantido." FERRAJOLI, Luigi. A pena em uma sociedade democrática; p.35. 


\section{BIBLIOGRAFIA}

BARATTA, Alessandro. Criminologia crítica e crítica do direito penal. Rio de Janeiro: Freitas Bastos, 1999.

BATISTA, Nilo. Mídia e sistema penal no capitalismo tardio. In: Discursos Sediciosos: Crime, Direito e Sociedade. Ano 7 n. 12. Rio de Janeiro: Revan, 2002.

BRANDÃO, Cláudio. Introdução ao Direito Penal. Rio de Janeiro: Forense, 2002.

DIETER, Maurício Stegemann. A Responsabilidade Penal da Pessoa Jurídica: uma crítica a Klaus Tiedemann. In: Revista Jurídica Themis. № 15 (2003-2004) Curitiba: JM, 2004.

FERRAJOLI, Luigi. A pena em uma sociedade democrática. In: Discursos Sediciosos: crime, direito e sociedade. Ano 7. n. 12. Rio de Janeiro: Revan, 2002.

FERREIRA, Gilberto. A Aplicação da Pena. Rio de Janeiro: Forense, 2004.

FRAGOSO, Heleno Cláudio. Lições de Direito Penal. 7 ed. Rio de Janeiro: Forense, 1985.

GARCÍA, Olga Lucia Gaitán. Direito penal contemporâneo: da tutela pena a uma lesão à proteção de riscos. In: Discursos Sediciosos: Crime, Direito e Sociedade. Ano 7 n. 12. Rio de Janeiro: Revan, 2002.

JAKOBS, Günther. Ciência do Direito e Ciência do Direito Penal. Barueri: Manole, 2003.

JAKOBS, Günther. Fundamentos do Direito Penal. São Paulo: Revista dos Tribunais, 2003.

JESUS, Damásio E. de. Direito Penal. 8ª ed. São Paulo: Saraiva, 1983.

LUHMANN, Niklas. Sociologia do Direito. Trad. Gustavo Bayer. Rio de Janeiro: Tempo Brasileiro, 1983.

MONTEIRO DE BARROS, Flávio Augusto. Direito Penal - Parte Geral. v.1. São Paulo: Saraiva, 1999. PERELMAN, Chaïm e OLBRECHTS-TYTECA, Lucie. Tratado da Argumentação: A Nova Retórica. São Paulo: Martins Fontes, 1996.

SANTOS, Juarez Cirino dos. A Criminologia Radical. Rio de Janeiro: Forense, 1981.

SANTOS, Juarez Cirino dos. Teoria de Pena: fundamentos políticos e aplicação judicial. Curitiba: ICPC/Lumen Juris, 2005. 